\title{
Can a genetically-modified organism-containing diet influence embryo development? A preliminary study on pre-implantation mouse embryos
}

\author{
B. Cisterna, ${ }^{1}$ F. Flach, ${ }^{1}$ L. Vecchio, ${ }^{2}$ S.M.L. Barabino, ${ }^{3}$ S. Battistelli, ${ }^{4}$ T. E. Martin, ${ }^{5}$ M. Malatesta, ${ }^{6}$ \\ M. Biggiogera ${ }^{1}$
}

${ }^{1}$ Dipartimento di Biologia Animale, Laboratorio di Biologia Cellulare e Neurobiologia, ed Istituto di Genetica Molecolare del CNR, University of Pavia, Italy; ${ }^{2}$ European Center for the Sustainable Impact of Nanotechnology, Rovigo, Italy; ${ }^{3}$ Dipartimento di Biotecnologia e Bioscienze, University of Milano-Bicocca, Italy; ${ }^{4}$ Istituto di Istologia e Analisi di Laboratorio, University of Urbino, Italy; ${ }^{5}$ Department of Molecular Genetics and Cell Biology, University of Chicago, Chicago, IL, USA; ${ }^{6}$ Dipartimento di Scienze MorfologicoBiomediche, Sezione di Anatomia e Istologia, University of Verona, Italy

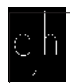

(C)2008 European Journal of Histochemistry

In eukaryotic cells, pre-mRNAs undergo several transformation steps to generate mature mRNAs. Recent studies have demonstrated that a diet containing a genetically modified (GM) soybean can induce modifications of nuclear constituents involved in RNA processing in some tissues of young, adult and old mice. On this basis, we have investigated the ultrastructural and immunocytochemical features of pre-implantation embryos from mice fed either GM or nonGM soybean in order to verify whether the parental diet can affect the morpho-functional development of the embryonic ribonucleoprotein structural constituents involved in premRNA pathways. Morphological observations revealed that the general aspect of embryo nuclear components is similar in the two experimental groups. However, immunocytochemical and in situ hybridization results suggest a temporary decrease of pre-mRNA transcription and splicing in 2-cell embryos and a resumption in 4-8-cell embryos from mice fed GM soybean; moreover, pre-mRNA maturation seems to be less efficient in both 2-cell and 4-8-cell embryos from GM-fed mice than in controls. Although our results are still preliminary and limited to the pre-implantation phases, the results of this study encourage deepening on the effects of food components and/or contaminants on embryo development.

Key words: Ultrastructure, pre-implantation embryos, immunocytochemistry, in situ hybridization, transcription, genetically modified soybean.

Correspondence: Marco Biggiogera,

Dipartimento di Biologia Animale, Laboratorio di Biologia Cellulare e Neurobiologia, Piazza Botta 10, 27100 Pavia, Italy

Tel.: +39.0382 .986322 .

Fax: +39.0382 .986325$

E-mail: marcobig@unipv.it

Paper accepted on November 17, 2008

European Journal of Histochemistry 2008; vol. 52 issue 4 (October-December):263-267
I n eukaryotic cells, gene primary transcripts (pre-mRNAs) undergo several transformation steps to generate mature mRNAs: pre-mRNA transcription, splicing (Fakan, 2004) and $3^{\prime}$ end processing (Cardinale et al., 2007) mostly occur on perichromatin fibrils (PF), ribonucleoprotein (RNP) fine fibrillar structures bordering the condensed chromatin, then the already spliced (pre)mRNA migrate either as PF or in the form of perichromatin granules ( $P G)$, roundish RNP structures which would also act as mRNA storage sites (Fakan, 2004). On the other hand, the interchromatin granules (IG), distributed as clusters in the interchromatin space, are not involved directly in pre-mRNA processing, representing storage and/or assembly sites for pre-splicing complexes (Puvion and Puvion Dutilleul, 1996). This molecular and structural apparatus devoted to mRNA production is highly sensitive to a variety of endogenous and exogenous factors. Interestingly, recent studies have demonstrated that a diet containing a genetically modified (GM), glyphosate-tolerant soybean (Padgette et al. 1995) can induce modifications of nuclear constituents involved in RNA processing in some tissues of young, adult and old mice (Malatesta et al., 2002, 2003, 2008; Vecchio et al., 2004). The replacement of the GM soybean with a non-GM one led to the reversion of such modifications (Malatesta et al., 2005). On this basis, we have investigated the possible effects of a GM soybean-containing diet on a crucial moment for cell nuclear activity: the reactivation process of premRNA transcription and maturation in pre-implantation mouse embryos (Schier, 2007). We have analyzed the ultrastructural and immunocytochemical features of 2-cell and 4-8-cell embryos from mice 
fed either GM or non-GM soybean in order to verify whether the parental diet can affect the morphofunctional development of the embryonic RNP structural constituents involved in pre-mRNA pathways.

\section{Materials and Methods}

Ten two month-old Swiss mice (five males and five females) were fed from their weaning (i.e. for 40-50 days) on a standard diet containing 14\% GM soybean obtained by the insertion of a bacterial gene conferring tolerance to glyphosate, the active ingredient of the herbicide Roundup (Padgette et al., 1995). In parallel, ten control mice (five males and five females) were fed on identical diet but containing non-GM soybean. The experiments were approved by the Italian Ministry of Health, in compliance with the European legislation on the care and use of laboratory animals.

One month-old female mice were injected with pregnant mare serum (Folligon, Intervet, Boxmeer, The Netherlands; 5 i.u.mL-1 in PBS) and, $46 \mathrm{~h}$ later, with human chorionic gonadotropin (Chorulon, Intervet, Boxmeer, The Netherlands; 5 i.u.mL-1 in PBS), and mated with males of the same experimental group. The embryos were recovered by flushing the oviducts with Hank's solution $24 \mathrm{~h}$ (2-cell) or $48 \mathrm{~h}$ (4-8-cell) after the presumed time of fertilization ( $12 \mathrm{~h}$ post human chorionic gonadotropin administration).

Embryos were fixed with 4\% paraformaldehyde and embedded in LR White resin. In order to evaluate BrU (5-bromouridine, Sigma-Aldrich, Buchs, Switzerland) incorporation as an index of transcriptional rate, some embryos were put in culture medium (DMEM) containing $1 \mathrm{mM} \mathrm{BrU}$, incubated at $37^{\circ} \mathrm{C}$ for $30 \mathrm{~min}$ and then processed for electron microscopy.

Ultrathin sections from 8-10 embryos from each experimental group were incubated as previously described (Malatesta et al., 2002) with antibodies directed against the following antigens: the phosphorylated form of polymerase II (Research Diagnostics Inc., Concord, MA, USA), the hnRNP core protein (Jones et al. 1980), the cleavage stimulation factor CStF (Veraldi et al., 2001) and the cleavage factor CF Im68 (Rüegsegger et al., 1998). A mouse monoclonal anti-BrdU antibody (Becton Dickinson, Franklin Lakes, NJ, USA) was used to detect the incorporated BrU molecules (Jensen et al., 1993). In situ hybridization for polyadenylated RNA was carried out as follows. Sections were pretreated with $2 \mu \mathrm{L}$ of a $10 \mathrm{mg} / \mathrm{mL}$ solution of tRNA in $\mathrm{H}_{2} \mathrm{O}, 2 \mu \mathrm{L} 20 \mathrm{X} \mathrm{SSC}, 4 \mu \mathrm{L} 50 \%$ dextran, $5 \mu \mathrm{L}$ deionized formamide and $2 \mu \mathrm{L} \mathrm{H} 2 \mathrm{O}$, for $15 \mathrm{~min}$ at room temperature. The biotinilated oligo $d(T)$ (Sigma-Aldrich, Buchs, Switzerland) was then added to give a $40 \mathrm{nM}$ concentration, and the grids were incubated for $3 \mathrm{~h}$ at $37^{\circ} \mathrm{C}$. After washings in formamide and SSC, the grids were reacted with a $5 \mathrm{~nm}$ gold-conjugated goat anti-biotin antibody (Aurion, Wageningen, The Netherlands). As controls, some grids were incubated in the absence of the probe, or pretreated with $0.1 \%$ RNase for 18 h. Sections were finally stained with EDTA for RNP visualization (Bernhard, 1969) and observed in a Philips Morgagni TEM equipped with a Megaview III camera for digital image acquisition. The gold grain contrast was digitally enhanced on micrographs by using Adobe Photoshop.

The labelling density over nucleoplasm and prenucleolar bodies (PNB) was evaluated: the surface area of each compartment was measured on 15 micrographs $(x 22,000)$ from each experimental group (5 embryos from each experimental group) by using AnalySIS Image processing (Soft Imaging System $\mathrm{GmbH}$ ). For background evaluation, the resin outside the tissue was considered. The gold grains over each compartment were counted and the labeling density was expressed as gold grain number $/ \mu m^{2}$. The mean \pm standard error of the mean (SE) values were calculated and statistical comparisons were performed by the one-way ANOVA test $(p \leq 0.05)$.

\section{Results and Discussion}

In this study we have evaluated the ultrastructural features of RNP nuclear structural constituents as well as the nuclear distribution of some factors involved in pre-mRNA transcription and processing in 2-cell and 4-8-cell embryos from mice fed either GM or non-GM soybean.

The general aspect of embryo nuclear components was similar in the two experimental groups. At the 2-cell stage, when newly transcribed RNA begins to undergo maturation and cytoplasmic export (Vautier et al., 1994), PF, PG and IG were well recognizable; at the 4-8 cell stage, when the 
transcriptional activity drastically increases (Fakan and Odartchenko, 1980), PF became more abundant. The formation of functional nucleoli required a longer time: at the 2-cell stage, nuclei contained several round, compact PNB known to be devoid of DNA and transcriptionally inactive (although some rRNA transcription has been demonstrated in late 2-cell stage); at the 4-8 cell stage, a transcriptionally active reticular formation appeared at the PNB periphery (Biggiogera et al., 1990; Fléchon and Kopecny, 1998).

The results of immunocytochemical and in situ hybridization analyses demonstrated quantitative differences between embryos from GM and nonGM fed mice (Table 1).

Polymerase II, responsible for pre-mRNA transcription, was distributed in all the samples on PF (not shown), the in situ form of pre-mRNA transcription and splicing (Fakan, 2004); however, the labelling was significantly lower in embryos from GM-fed mice than in controls at the 2-cell stage, while no significant difference was found at the 4-8 cell stage. Accordingly, BrU incorporation in PF containing newly transcribed RNA was significantly lower in 2-cell embryos from GM-fed mice, whereas in 4-8-cell embryos the values were similar in the two experimental groups (Figure $1 a, b$ ). HnRNPs mostly occurred on PF and, interestingly, on IG in all samples (Figure $1 \mathrm{a}, \mathrm{b}$ ), but, again, embryos from GM-fed mice showed a weaker labelling at both 2-cell and 4-8-cell stage. No significant labelling for polymerase II, BrU and hnRNPs was found in PNB of any embryos, apart from 4-8-cell embryos, where some BrU incorporation occurred at the PNB periphery (not shown), in agreement with the already described resumption of pre-rRNA transcription at this stage (Fléchon and Kopecny, 1998).

These results suggest a temporary decrease of pre-mRNA transcription and splicing in 2-cell embryos from mice fed GM soybean as well as resumption at the 4-8-cell stage, although hnRNP levels remain lower in embryos from GM fed mice.

Further investigation on pre-mRNA processing demonstrated that both cleavage factors CFIm68

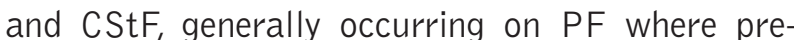
$\mathrm{mRNa} 3^{\prime}$ end processing takes place (Cardinale et al., 2007), showed lower nucleoplasmic levels in both 2-cell and 4-8 cell embryos from GM-fed mice (Figure $1 \mathrm{c}, \mathrm{d}$ ). Interestingly, in all embryos some cleavage factors were also found on IG and even in
Table 1. Mean values $\pm S E$ of labelling densities (gold grains $/ \mu^{2}$ ) on pre-implantation embryos from mice fed GM or non-GM (control) soybean. Background levels were negligible for all probes.

\begin{tabular}{lccccc}
\hline & & \multicolumn{2}{c}{ 2-cell embryos } & \multicolumn{2}{c}{4 -8-cell embryos } \\
& & nucleoplasm & PNB & nucleoplasm & PNB \\
\hline Anti-polymerase II & control & $3.79 \pm 0.18$ & $0.02 \pm 0.01$ & $4.43 \pm 0.34$ & $0.00 \pm 0.00$ \\
& GM-fed & $2.18 \pm 0.39$ & $0.03 \pm 0.01$ & $3.74 \pm 0.33$ & $0.03 \pm 0.02$ \\
& & $p<0.001$ & $p=0.772$ & $p=0.164$ & $p=0.389$ \\
Anti-BrU & control & $7.46 \pm 0.23$ & $0.04 \pm 0.03$ & $2.76 \pm 0.18$ & $0.57 \pm 0.30$ \\
& GM-fed & $5.68 \pm 0.19$ & $0.03 \pm 0.02$ & $2.41 \pm 0.19$ & $0.42 \pm 0.19$ \\
& & $p<0.001$ & $p=0.347$ & $p=0.226$ & $p=0.778$ \\
Anti- hnRNP & control & $10.79 \pm 0.41$ & $0.00 \pm 0.00$ & $5.10 \pm 0.42$ & $0.06 \pm 0.04$ \\
& GM-fed & $4.92 \pm 0.40$ & $0.04 \pm 0.02$ & $3.16 \pm 0.20$ & $0.03 \pm 0.02$ \\
& & $p<0.001$ & $p=0.326$ & $p=0.001$ & $p=0.341$ \\
Anti-CStF & control & $4.45 \pm 0.39$ & $13.66 \pm 0.94$ & $14.98 \pm 2.25$ & $17.07 \pm 1.43$ \\
& GM-fed & $2.75 \pm 0.33$ & $10.51 \pm 0.58$ & $6.09 \pm 0.71$ & $16.04 \pm 1.36$ \\
& & $p=0.011$ & $p=0.119$ & $p=0.030$ & $p=0.786$ \\
Anti-CFlm68 & control & $3.08 \pm 0.27$ & $10.96 \pm 0.70$ & $7.31 \pm 0.60$ & $13.07 \pm 2.14$ \\
& GM-fed & $1.05 \pm 0.08$ & $6.03 \pm 0.65$ & $2.36 \pm 0.23$ & $5.61 \pm 0.68$ \\
& & $p<0.001$ & $p=0.017$ & $p<0.001$ & $p=0.030$ \\
Polyadenilated & control & $2.17 \pm 0.19$ & $0.13 \pm 0.10$ & $5.48 \pm 0.64$ & $0.15 \pm 0.11$ \\
RNA & GM-fed & $1.61 \pm 0.20$ & $0.04 \pm 0.04$ & $2.24 \pm 0.21$ & $0.13 \pm 0.07$ \\
& & $p=0.043$ & $p=0.556$ & $p<0.001$ & $p=0.914$ \\
\hline & & & & &
\end{tabular}

PNB (Figure $1 \mathrm{~d}$ ), suggesting a possible role as storage sites as previously observed for nucleoplasmic RNPs (Biggiogera et al., 1994). According to the reduction in cleavage factors, a significant reduction in polyadenilated $m R N A$, specifically located on PF (Visa et al., 1993), was found in the embryos from GM-fed mice (Figure $1 \mathrm{e}, \mathrm{f}$ ). These data suggest that pre-mRNA maturation may be less efficient in both 2-cell and 4-8-cell embryos from GM-fed mice than in controls.

At present, we do not know which could be the factor(s) present in the GM soybean capable of influencing pre-mRNA pathways in pre-implantation mouse embryos. Among these, the hypothesis of the presence in the chow of traces of the herbicide to which the soybean has been rendered tolerant (Padgette et al., 1995) has been supported by a recent study (Malatesta et al., 2008). This herbicide inhibits transcription, slows down cell cycle and, most interestingly, delays the onset of transcriptional activity in the sea urchin embryos (Marc et al., 2004, 2005). However, it can not be excluded that the differences in some nutrient components (Lappé et al., 1998) between the two soybeans could influence early embryo development.

Preliminary observations indicate that a GM soybean-containing diet does not affect mouse fertility, parturition time or litter health, thus suggesting that the depression of pre-mRNA transcription and 

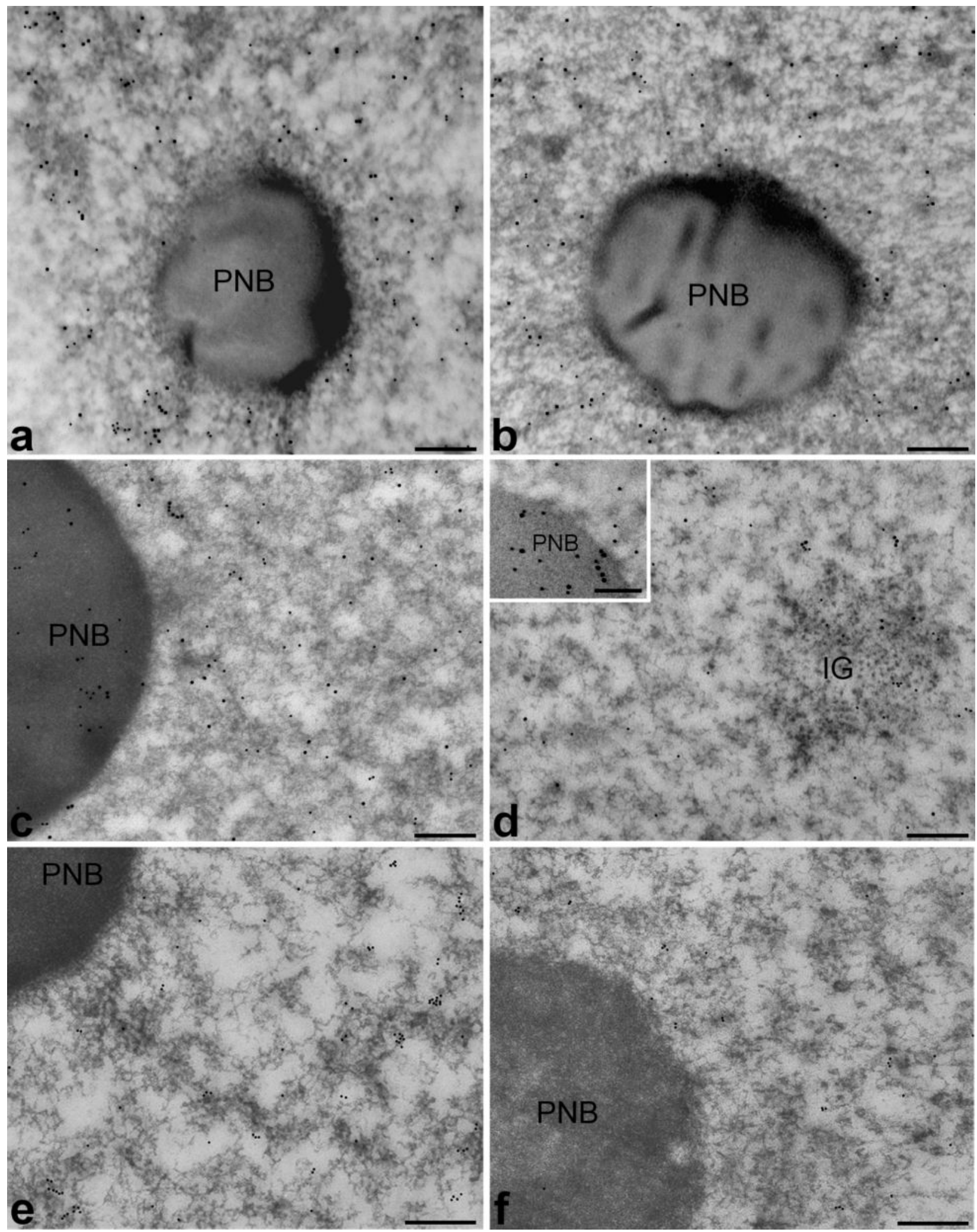

Figure 1. (a, b) 2-cell embryos from control (a) and GM-fed (b) mice, double immunolabelling with anti-hnRNP (12 nm) and anti-BrdU $(6 \mathrm{~nm})$ antibodies; both probes specifically bind PF, whereas PNB are devoid of any signal. c, d) 4-8-cell embryos from control (c) and GM-fed (d) mice, double immunolabelling with anti-CStF $(6 \mathrm{~nm})$ and anti-CFIm68 $(12 \mathrm{~nm})$ antibodies; the cleavage factors occurs not only on PF but also on IG and PNB. e, f) 4-8-cell embryos from control (e) and GM-fed (f) mice, in situ hybridization for polyadenilated RNA (6 nm); the labelling is present on PF but not on PNB. Note that all probes are less abundant in embryos from GM-fed mice. Bars: $0.5 \mu \mathrm{m}$; inset bar: $0.1 \mu \mathrm{m}$. 
processing is a transient phenomenon which does not affect foetal development; however, the results of this study encourage deepening on the effects of food components and/or contaminants on embryo development.

\section{Acknowledgements}

We thank Prof. Christine Milcarek for kindly providing us with anti-CStF antibody. This work was supported by the Agenzia Servizi Settore Agroalimentare delle Marche, Italy.

\section{References}

Bernhard W. A new staining procedure for electron microscopic cytology. J Ultrastruct Res 1969;27:250-65.

Biggiogera $\mathrm{M}$, Martin TE, Gordon J, Amalric $\mathrm{F}$, Fakan S. Physiologically inactive nucleoli contain nucleoplasmic ribonucleoproteins: immunoelectron microscopy of mouse spermatids and early embryos. Exp Cell Res 1994;213:55-63.

Cardinale S, Cisterna B, Bonetti $\mathrm{P}$, Aringhieri C, Biggiogera M, Barabino SM. Subnuclear localization and dynamics of the PremRNA $3^{\prime}$ end processing factor mammalian cleavage factor I 68kDa subunit. Mol Biol Cell 2007;18:1282-92.

Fakan S. The functional architecture of the nucleus as analysed by ultrastructural cytochemistry. Histochem Cell Biol 2004;122:83 93

Fakan S, Odartchenko N. Ultrastructural organization of the cell nucleus in early mouse embryos. Biol Cell 1980;37:211-8.

Fléchon JE, Kopecny V. The nature of the 'nucleolus precursor body' in early preimplantation embryos: a review of fine-structure cytochemical, immunocytochemical and autoradiographic data related to nucleolar function. Zygote 1998;6:183-91.

Jensen PO, Larsen J, Christiansen J, Larsen JK. Flow cytometric measurement of RNA synthesis using bromouridine labelling and bromodeoxyuridine antibodies. Cytometry 1993;14:455-8.

Jones RE, Okamura CS, Martin TE. Immunofluorescent localization of the proteins of nuclear ribonucleoprotein complexes. J Cell Biol 1980;86:235-43.

Lappé MA, Bailey EB, Childress C, Setchell KDR. Alterations in clinically important phytoestrogens in genetically modified, herbicidetolerant soybeans. J Med Food 1998;1:241-5.

Malatesta M, Biggiogera M, Manuali E, Rocchi MBL, Baldelli B Gazzanelli $G$. Fine structural analyses of pancreatic acinar cell nuclei from mice fed on GM soybean. Eur J Histochem 2003;47: 385-8.

Malatesta M, Caporaloni C, Gavaudan S, Rocchi MBL, Tiberi C, Gazzanelli G. Ultrastructural morphometrical and immunocytochemical analyses of hepatocyte nuclei from mice fed on genetically modified soybean. Cell Struct Funct 2002;27:173-80.

Malatesta M, Tiberi C, Baldelli B, Battistelli S, Manuali E, Biggiogera $B$. Reversibility of hepatocyte nuclear modifications in mice fed on genetically modified soybean. Eur J Histochem 2005;49:237-42.

Malatesta M, Boraldi F, Annovi G, Baldelli B, Battistelli S, Biggiogera $M$, et al. A long-term study on female mice fed on a genetically modified soybean: effects on liver ageing. Histochem Cell Biol doi:10.1007/s00418-008-0476-x.

Malatesta M, Perdoni F, Santin G, Battistelli S, Muller S, Biggiogera M. Hepatoma tissue culture (HTC) cells as a model for investigating the effects of low concentrations of herbicide on cell structure and function. Toxicol in vitro doi:10.1016/j.tiv.2008.09.006.

Marc J, Bellé R, Morales J, Cormier P, Mulner-Lorillon 0. Formulated glyphosate activates the DNA-response checkpoint of the cell cycle leading to the prevention of $\mathrm{G} 2 / \mathrm{M}$ transition. Toxicol Sci 2004;82:436-42.

Marc J, Le Breton M, Cormier P, Morales J, Bellé R, Mulner-Lorillon 0 . A glyphosate-based pesticide impinges on transcription. Toxicol Appl Pharmacol 2005;203:1-8.

Padgette SR, Kolacz KH, Delannay X, Re DB, LaVallee BJ, Tinius CN, et al. Development, identification and characterization of a glyphosate-tolerant soybean line. Crop Sci 1995;35:1451-61.

Puvion E, Puvion-Dutilleul F. Ultrastructure of the nucleus in relation to transcription and splicing: roles of perichromatin fibrils and interchromatin granules. Exp Cell Res 1996;229:217-25.

Rüegsegger U, Blank D, Keller W. Human pre-mRNA cleavage factor Im is related to spliceosomal SR proteins and can be reconstituted in vitro from recombinant subunits. Mol Cell 1998;1:243-53.

Schier AF. The maternal-zygotic transition: death and birth of RNAs. Science $2007 ; 316: 406-7$.

Vautier D, Besombes D, Chassoux D, Aubry F, Debey P. Redistribution of nuclear antigens linked to cell proliferation and RNA processing in mouse oocytes and early embryos. Mol Reprod Dev 1994;38:119-30.

Vecchio L, Cisterna $B$, Malatesta M, Martin TE, Biggiogera M. Ultrastructural analysis of testes from mice fed on genetically modified soybean. Eur J Histochem 2004;48:449-53.

Veraldi KL, Arhin GK, Martincic K, Chung-Ganster LH, Wilusz J, Milcarek C. HnRNP F influences binding of a 64-kilodalton subunit of cleavage stimulation factor to mRNA precursors in mouse $B$ cells. Mol Cell Biol 2001;21:1228-38.

Visa N, Puvion-Dutilleul F, Harper F, Bachellerie JP, Puvion E. Intranuclear distribution of poly(A) RNA determined by electron microscope in situ hybridization. Exp Cell Res 1993;208:19-34. 